\title{
AS MULHERES DOCENTES DO IFPR E A QUESTÃO DE GÊNERO: protagonistas ou coadjuvantes no processo formativo dos cursos técnicos?
}

\section{RESUMO}

Tânia Gracieli Vega Incerti tania.incerti@ifpr.edu.br Universidade Tecnológica Federal do Paraná (UTFPR), Curitiba, Paraná, Brasil.

Ana Maria de Carvalho ana.carvalho@ifpr.edu.br Universidade Tecnológica Federal do Paraná (UTFPR), Curitiba, Paraná, Brasil.

\section{Lindamir Salete Casagrande} lindasc@utfpr.edu.br Universidade Tecnológica Federal do Paraná (UTFPR), Curitiba,

Paraná, Brasil

\begin{abstract}
Este artigo tem por finalidade apresentar os resultados de uma pesquisa, a qual objetivou conhecer o lócus das mulheres docentes do Instituto Federal do Paraná (IFPR) - Campus Curitiba. O corpo docente do Campus constitui-se por duzentos e vinte e cinco servidores/as, disto cento e sete são mulheres e cento e dezoito são homens. Ao analisarmos esses números observamos inicialmente que não há uma prevalência no que se refere às relações de gênero, entretanto cabe investigar em que áreas elas e eles estão atuando. A pesquisa foi feita a partir da coleta de dados documentais/institucionais, que ao se ter em mãos os resultados, para além da disposição em gráficos, necessariamente nos leva a muitas reflexões que denotam uma análise qualitativa. Acreditamos, por fim, que os resultados desta pesquisa podem nos levar a refletir sobre a inserção da mulher na Ciência e Tecnologia, visto que o espaço sócio ocupacional pesquisado é um local de educação formal, com vistas à ciência e ao desenvolvimento de tecnologias.
\end{abstract}

PALAVRAS-CHAVE: Docentes. Educação profissional e tecnológica. Espaço ocupacional. 


\section{INTRODUÇÃO}

O presente artigo mostrará o desenvolvimento de uma pesquisa que tem por objetivo conhecer o lócus das mulheres docentes do Instituto Federal do Paraná (IFPR) - Campus Curitiba, buscando identificar se os papéis que elas desenvolvem no processo de ensino e aprendizagem são de protagonistas no ensino dos cursos técnicos, sendo coordenadoras dos cursos e/ou lecionando em proporção de igualdade nas disciplinas técnicas ou ocorrem de forma coadjuvante atuando apenas no ensino das disciplinas chamadas núcleo comum.

Destaca-se que o IFPR, como outras instituições federais de educação tecnológica e profissional é fruto da Lei 11.892 de 2008 que cria os Institutos Federais de Educação e introduz um novo modelo de educação profissional no país, que oferece cursos técnicos de nível médio, cursos superiores de tecnologia, licenciaturas, mestrados e doutorados, possibilitando ao/a estudante construir um itinerário formativo em uma única instituição de ensino. Atualmente o IFPR está em funcionamento com vinte e cinco munícipios sendo Curitiba o primeiro e maior Campus. Esse Campus disponibiliza vinte e quatro cursos técnicos ${ }^{1}$, tanto na forma de oferta integrada quanto subsequente, dois cursos superiores e uma especialização. O corpo docente do Campus constitui-se por duzentos e vinte e cinco servidores/as, disto cento e sete são mulheres e cento e dezoito são homens. Ao analisarmos esses números observamos inicialmente que não há uma prevalência no que se refere às relações de gênero. Lembra-se aqui que igualdade, tal como preconiza Joan Scott (2005), para além de uma expressão meramente numérica, diz respeito a possuir um grau semelhante de uma qualidade ou atributo especificado ou implícito; estar no mesmo nível em termos de posição, dignidade, poder, habilidade, realização ou excelência; ter os mesmos direitos ou privilégios. Ao se ter em vista determinada conjuntura social, sua definição é menos precisa e apresenta alguns paradoxos.

Tendo em vista o objetivo proposto neste artigo, qual seja, entender se a atuação das docentes ocorre enquanto protagonistas ou coadjuvantes no processo de ensino aprendizagem se faz proeminente conhecer como se institui a educação, como se deu a inserção das mulheres nas universidades o no mundo do trabalho visto ser histórica a negação à mulher em participar do mundo acadêmico e ser subestimada e desvalorizada no mundo de trabalho. Para tal, traremos brevemente um histórico da educação profissional e tecnológica, apresentaremos um breve relato acerca da Instituição em tela e os dados iniciais acerca do quantitativo do corpo docente no Campus Curitiba. Para o embasamento teórico, discussão conceitual e análise, utilizaremos a pesquisa bibliográfica para o resgate de alguns conceitos acerca da Educação profissional técnica e tecnológica, o recorte histórico da inserção da mulher na ciência e a divisão sexual do trabalho.

\section{A ESCOLA, A EDUCAÇÃO FORMAL E A EDUCAÇÃO PROFISSIONAL²}

Ao nos atermos ao histórico das primeiras indicações do sistema escolar, Mariano Fernandes Enguita (1989) aponta-nos que estas são oriundas do Baixo Império Romano e Império Carolíngio, ambos burocráticos que necessitavam de um sistema escolar para sua reprodução, necessitavam de funcionários, os quais conhecessem ao menos a leitura e escrita e a origem das leis. Outros sistemas 
surgiram posteriormente, principalmente alicerçados por bases religiosas, como por exemplo na Alemanha a partir da Reforma Protestante, e com os católicos observa-se a expansão do ensino dos Jesuítas. Ainda, a partir da formação dos estados nacionais modernos que reuniam em um mesmo espaço geográfico, povos com culturas, costumes, leis e línguas totalmente diferentes entre si, desencadeiase outro processo de expansão do ensino, o qual ficou sob a atribuição da escola primeiramente.

Além das funções primeiras destinadas à educação, tal como descrito acima, Enguita (1989, p. 130) destaca outra intenção da educação, qual seja, "[...] a necessidade de dominar uma certa quantidade de conhecimentos e destrezas para desenvolver-se em qualquer trabalho ou fora dele em uma sociedade industrializada e urbanizada". Essa tarefa era da escola, família ou outros meios de comunicação de massas.

Quando temos em vista o histórico de surgimento da Educação formal, apoiamo-nos no que nos apresenta Enguita (1989) o qual aponta que com o surgimento da industrialização e com ela novas formas de produção da educação para o trabalhador têm necessidade de uma nova versão, pois nesse cenário histórico, a indústria pede um novo modelo de trabalhador. Além de piedoso e resignado esse trabalhador deveria aceitar trabalhar para o outro e nas condições que lhe for imposta. As crianças, deveriam ser modeladas desde pequenas, para que quando adultas venham a atender às necessidades da nova ordem capitalista e as relações de trabalho que com ela se estabeleciam. A escola destaca-se como o instrumento idôneo que permitiria esse ajustamento.

Conforme Enguita (1989) é preciso sempre ter em vista é que as escolas antecederam o capitalismo e a indústria, e continuaram a se desenvolver com eles, mas por razões a eles alheias. Entretanto, a partir de um certo desenvolvimento do capitalismo, esse, a partir de suas necessidades em termos de mão de obra, deu forma à escolarização. $O$ autor aponta alguns elementos para que possamos compreender essa influência do capitalismo no processo de escolarização, dentre eles menciona: forte influência do capitalismo exercida sobre o poder público; investimentos de recursos financeiros em grande número de iniciativas privadas; a escola subordinada aos interesses capitalistas como um caminho para o trabalho assalariado; as escolas servem como campo de treinamento de mão de obra para as empresas capitalistas; o paradigma da eficiência retratado pelas empresas tinha grande legitimidade social, tornando-as instituições desejáveis ou inevitáveis; a escola de hoje é resultado de um produto provisório de conflitos ideológicos, organizados, organizativos e sociais.

Após a retomada histórica apontando o fim do sistema feudal e suas características e o início do sistema capitalista, Demerval Saviani (2007, p. 159) destaca que "[...] a Revolução Industrial correspondeu a uma Revolução Educacional: aquela colocou a máquina no centro do processo produtivo; esta erigiu a escola em forma principal e dominante de educação". Esse processo forçou a ligação da escola com os modos de produção. Também, conforme destaca o autor é possível identificar ainda uma dualidade no processo de formação e escola primária: uma destinada ao trabalhador, a partir das escolas profissionais e outra destinada aos futuros dirigentes, baseada na formação geral, mais intelectual.

Nesse sentido, Dante Henrique Moura, Domingos Lima Filho e Mônica Silva (2015, p. 1059) ao tratar da educação escolar, afirmam que essa passou de produto de luxo, que visava atender aos interesses da classe dirigente para algo essencial à 
sociabilidade humana. Conforme explicitam, "Na fase atual de desenvolvimento das forças produtivas, ancoradas na ciência, na técnica e na tecnologia, sob o domínio do sistema capital, a escola vem tornando-se 'essencial' à sociedade humana". Essa condição de essencial ocorre especialmente para atender aos interesses do modo de produção capitalista que requer um sistema educacional dividido e moldado por classes (trabalhadores e dirigentes), assim, separe a educação a partir da divisão entre trabalho intelectual e manual, do trabalho simples e trabalho complexo, cultura geral e cultura técnica, ou seja, uma formação fragmentada, mas ao mesmo tempo dialética.

Diante disso, é possível inferir que as trajetórias escolares serão diferentes dada a realidade e contexto em que a população está inserida. Assim, de acordo com Acácia Kuenzer (2005) para aquelas pessoas com maior acesso aos bens culturais e econômicos, a trajetória, quase sempre perpassa o acesso a uma educação propedêutica e possível ingresso em cursos superiores. Para a maioria da população, tem-se por destino uma educação básica, muitas vezes precária, associada à formação para o trabalho, a partir de cursos técnicos e ou cursos tecnólogos.

Em que pese especialmente ao ensino médio profissional e técnico, foco específico de análise nesse artigo, recorremos as suas Diretrizes Curriculares, nas quais evidencia-se que a educação profissional é, antes de tudo, educação. Assim sendo, rege-se pelos princípios explicitados na Constituição Federal e na Lei de Diretrizes e Bases da Educação Nacional. Desta forma, para a formulação e desenvolvimento dos projetos pedagógicos das escolas e instituições de educação profissional e proposição de cursos técnicos, deve-se considerar os princípios contidos no artigo 3ㅇ da Lei de Diretrizes e Bases da Educação (LDB) de 1994, quais sejam: a igualdade de condições para o acesso e a permanência na escola, a liberdade de aprender e ensinar, a valorização dos profissionais da educação.

De acordo com a LDB (Lei 9.394/96) a Educação Profissional e Tecnológica, será desenvolvida por meio de cursos e programas de: I - formação inicial e continuada de trabalhadores; II - educação profissional técnica de nível médio; e III - educação profissional tecnológica de graduação e de pós-graduação. Ressaltase que o ensino técnico/educação profissional, conforme Domingos Leite Lima Filho e Gilson Leandro Queluz (2010), constitui-se como um local privilegiado de contradições sociais, econômicas, políticas, culturais e filosóficas. Essa contradição justifica-se especialmente pelo fato de que essa modalidade de ensino tem por fim tanto a qualificação do trabalhador/a como o processo de transmissão/apropriação do conhecimento.

Diante ao exposto ratificamos que é nesse espaço contraditório em que as professoras e os professores do IFPR estão inseridos e desenvolvem suas funções, as quais muitas vezes vão além do lecionamento de aulas, podendo fazer parte de funções de gestão e/ou coordenação de curso.

\section{O INSTITUTO FEDERAL DO PARANÁ}

O Instituto Federal do Paraná, como outras instituições federais de educação profissional e tecnológica é fruto da Lei 11.892 de 2008. Com a promulgação da referida lei, são criados 38 Institutos Federais de Educação, Ciência e Tecnologia, pela transformação dos antigos Centros Federais de Educação Tecnológicas 
(CEFETs); escolas agrotécnicas e escolas técnicas. Isto significou a introdução de um novo modelo de educação profissional no país, que oferece cursos técnicos de nível médio, cursos superiores de tecnologia, licenciaturas, mestrados e doutorados, possibilitando ao estudante construir um itinerário formativo que se aproxime de suas expectativas e necessidades, além de proporcionar que o estudante desde o nível médio tenha acesso a uma formação de qualidade, com professores pós-graduados, bem como participe ativamente de atividades e projetos de pesquisa e extensão.

É com essas características e nesse espaço que reside o Instituto Federal do Paraná. O processo histórico que culminou na criação do IFPR, apresenta uma particularidade que o diferencia de muitos dos Institutos criados recentemente no Brasil, aqui o nascimento da instituição data de 1869 , mais de um século de existência. Inicialmente surgiu enquanto criação da antiga Colônia Alemã e denominou-se Escola-alemã, passou por mudanças pedagógicas e administrativas e denominações diferentes, até que chegou a ser incorporada pela Universidade Federal do Paraná como Escola Técnica. Este vínculo com a Universidade durou 68 anos, até que em 2008, a Instituição ganhou autonomia didático-pedagógica, financeira, disciplinar, administrativa e patrimonial. A transformação da Escola Técnica da Universidade Federal do Paraná em Instituto Federal do Paraná fez parte de um movimento nacional de Reestruturação e Expansão da Rede Federal de Educação Profissional, Científica e Tecnológica no Brasil, que se estendeu por todos os estados do país.

Atualmente o IFPR está em funcionamento com vinte e cinco campi ${ }^{3}$, Assis Chateaubriand, Astorga, Barracão, Campo Largo, Capanema, Cascavel, Colombo, Coronel Vivida, Curitiba, Foz do Iguaçu, Goioerê, Irati, Ivaiporã, Jacarezinho, Jaguariaíva, Londrina, Palmas, Paranaguá, Paranavaí, Pinhais, Pitanga, Quedas do Iguaçu, Telêmaco Borba, Umuarama e União da Vitória e ainda a modalidade do Ensino a Distância (EAD). E os cursos ofertados nos diversos campi da instituição englobam os níveis médio, superior e pós-graduação.

Como a análise deste artigo partirá da realidade do IFPR- Campus Curitiba é desse que trazer-se-á um pouco da história e suas características. Curitiba foi o primeiro campus do IFPR a ser implantado. Localiza-se na região central de Curitiba, possibilitando fácil acesso aos/às seus/suas estudantes. A instituição encontra-se em funcionamento em um prédio histórico e atualmente tem sua parte pedagógica e de laboratórios em um mesmo espaço físico. O que não ocorreu desde o início de suas atividades, visto que o Campus, por questões de acomodação da Reitoria, era dividido em dois locais de funcionamento e alguns cursos não tinham laboratório para as suas atividades práticas desde o primeiro ano de curso.

\section{TRABALHO E DIVISÃO SEXUAL DO TRABALHO}

Para o alcance dos nossos objetivos neste artigo, utilizaremos a conceituação da categoria trabalho e também uma análise acerca da vertente divisão sexual do trabalho.

A problematização do trabalho contará com a concepção trazida especialmente por Gaudêncio Frigotto (2007, p. 242) o qual à luz da perspectiva 
marxista, compreende que o trabalho não se reduz a atividade laborativa ou emprego, mas sim permeia todas as dimensões do ser humano.

Não obstante, a história do trabalho humano efetivou-se até o presente sob a cisão da espécie humana em classes sociais, desde as sociedades escravocratas até a atual forma de trabalho alienado sob o capitalismo. Na fase do capitalismo, essa relação de classe torna-se a fonte de expropriação do trabalho mediante a apropriação da mais-valia absoluta ou relativa.

Conforme Frigotto (2007), a partir dos pressupostos marxistas, a transformação que o homem exerce sobre a natureza é classificada como trabalho, cujos objetivos coletivos humanos são fundamentais para a concepção de práxis, a tecnologia é o produto dessa ação.

No contexto brasileiro a análise de Frigotto (2007) aponta a existência de um processo de industrialização tardio e um processo de desenvolvimento do capitalismo dependente e o Estado sempre subordinado aos interesses das classes dominantes e favorecendo a ampliação e concentração de capital e renda em detrimento da desigualdade social entre as classes.

O pensamento neoliberal assumido pela classe dominante brasileira e pelo Estado, direcionado pela tese do ajuste mediante a reforma do estado, concretizado por meio de privatizações do patrimônio público, ampliação do poder do capital sobre o trabalho e diminuição dos direitos trabalhistas e internacionalização da economia sob o domínio monetarista e fiscal em nome do pagamento dos serviços da dívida externa.

Nesse sentido e apresentando certas peculiaridades temos em vista a conceituação da divisão sexual do trabalho. Dentre as estudiosas que se dedicam a essa temática e os estudos desenvolvidos sobre as relações desiguais motivadas pela diferenciação sexual no trabalho, Helena Hirata e Danièle Kergoat (2007) apresentam-se como referências. Para essas autoras a definição de divisão sexual do trabalho mostra que a forma de divisão do trabalho social é decorrente das relações sociais entre os sexos e ainda mais importante, trata-se de fator prioritário para a sobrevivência da relação social entre os sexos.

Conforme Hirata e Kergoat (2007) esse formato de organização é modulado histórica e socialmente. Tem como características a designação prioritária dos homens à esfera produtiva e das mulheres à esfera reprodutiva e simultaneamente a apropriação pelos homens das funções com maior valor social adicionado (políticos, religiosos, militares etc.)

Na divisão sexual do trabalho há um modo diferencial de entrada de homens e mulheres ao mundo do trabalho, tal qual a analogia trazida pelas autoras no que tange à divisão desigual entre homens e mulheres ao trabalho no âmbito doméstico. Hirata e Kergoat (2007) apontam que essas desigualdades são sistemáticas e que a hierarquização das atividades, por sexos, criou um sistema de gêneros.

A hierarquização e desvalorização do trabalho feminino são milenar, Enguita (1989) expõe que na Roma Antiga as famílias camponesas inseriam os filhos homens acompanhando o pai no trabalho com a terra e as filhas moças permaneciam com a mãe a ajuda-la nas tarefas domésticas.

Londa Schiebinger $(2001$, p. 74$)$ alerta-nos que na era da sociedade moderna industrial, fatores como a "[...] divisão de trabalho entre emprego e lar permanece um obstáculo ao ingresso das mulheres nas profissões". 
Direcionando nosso olhar na análise da inserção feminina nas instituições cientificas se verifica através dos séculos "[...] que a estrutura dessas instituições pode encorajar ou desencorajar a participação das mulheres" (SCHIEBINGER, 2001, p. 74). Para a mesma autora, alguns fatores apresentam-se presentes de forma interdependente nesse processo, e influenciam diretamente o êxito das mulheres na ciência, dentre eles: o prestígio das instituições científicas, os acasos de guerra e paz, o clima político e a estrutura econômica da família.

Acresce ainda a autora que as responsabilidades domésticas versus profissionais, o relógio da carreira acadêmica versus o relógio biológico, são muitos dos problemas que as mulheres enfrentam na ciência. E por fim que "A situação das mulheres mudou junto com as condições sociais e os climas de opinião". (SCHIEBINGER, 2001, p. 74).

\section{AS MULHERES NA EDUCAÇÃO, CIÊNCIA E TECNOLOGIA ${ }^{4}$}

Conforme apontam Carla Cabral e Walter Bazzo (2005, p. 3) historicamente, as mulheres foram afastadas do círculo criativo e líder da produção científica e tecnológica. Isso limitou sua atuação fora da esfera privada da casa e foi, séculos após séculos, evidenciado pela sua ausência e condução em carreiras como física, química, biologia, matemática, engenharia e computação. Dada essa predominância masculina, essas áreas, nas palavras dos autores "[...] foram desenvolvidas ao sabor de valores considerados masculinos". Dentre eles: certeza, eficiência, controle e ordem. Para que se pudesse chegar a essa constatação, os movimentos feministas tiveram um importante papel. Essa pauta foi bandeira principalmente da segunda onda do feminismo.

A partir da contribuição de Marília Gomes de Carvalho e Lindamir Salete Casagrande (2011) as quais pontuam os avanços e desafios para as mulheres nas ciências, observa-se que além das barreiras impostas pela cultura de uma sociedade patriarcal e machista que não permitia às mulheres frequentarem ambientes acadêmicos, outra questão de gênero interferiu (e interfere) diretamente e apresenta dificuldades para as mulheres se dedicarem à ciência: a divisão sexual do trabalho, que estabelece o trabalho da esfera pública aos homens e os da esfera privada às mulheres. Assim, a divisão sexual do trabalho na família as limitava aos trabalhos domésticos e aos cuidados dos seus membros dependentes. Nesse sentido, ao trazerem a história das mulheres na ciência as autoras destacam que as condições e a qualidade do tempo do trabalho científico são diferentes para as mulheres e para os homens.

Carla Cabral e Walter Bazzo (2005) destacam que o acesso à leitura e à escrita, por volta de meados do século XVII, foi mudando o lugar da mulher nas sociedades e, por consequência, sua participação em carreiras científicas e tecnológicas. Conforme mencionamos anteriormente, o acesso das mulheres em todas as carreiras hoje está aberto, no entanto, muitas barreiras restringem sua participação na produção do conhecimento científico e tecnológico, essa restrição é hierárquica e territorial, num universo masculino no que se refere à pesquisa e ao trabalho.

Marília Gomes de Carvalho (2011, p. 408) informa que "Após a Revolução Industrial, já consolidada na Europa no século XIX, ocorre um desenvolvimento tecnológico essencial para o aumento da produtividade e consequente aumento 
da acumulação da riqueza, fundamental para o capitalismo". No entanto, as mulheres também não participaram das invenções e inovações tecnológicas, pois suas atividades continuavam limitadas à esfera privada do espaço doméstico e das funções da maternidade.

Nessa mesma linha de argumentação Carvalho (2011, p. 408) ratifica que "[...] a construção social do gênero, ou seja, como os homens aprendem o que devem ser na sociedade e como as mulheres, da mesma forma, aprendem os padrões femininos, ocorreu na sociedade ocidental de uma maneira binaria e dicotômica".

Ao analisarmos as características socialmente associadas ao feminino, como por exemplo, delicadeza, fraqueza física, intuição, afetividade é possível concluirmos de maneira apressada, como argumenta a mesma autora, que elas não podem estar presentes na construção científico-tecnológica, já que elas estão muito mais ligadas e atendem as necessidades da esfera privada da casa e são importantes para a maternidade. Já ao pensarmos nas características ditas masculina, destacadas, dentre outras, agressividade, competitividade, força física, racionalidade e objetividade, essas sim, são tidas como importantes para a esfera pública, estando presentes no mundo científico e tecnológico.

Quando pensamos no processo de exclusão das mulheres na ciência, Betina Stefanello Lima (2008) contribui para o nosso entendimento e destaca, que essa pode ser dividida em duas partes: a) exclusão vertical, definida como sendo aquela que se refere à sub-representação das mulheres em postos de prestígio e poder, mesmo nas carreiras consideradas femininas; e b) horizontal, referente aquela em que se observa um número escasso de mulheres em determinadas áreas do conhecimento, em geral, de maior reconhecimento para a economia capitalista, as consideradas ciências "duras" - exatas e engenharias.

Considerando esse contexto, é possível, partindo de uma análise que leve em conta a divisão sexual nos processos de formação, entendermos tanto a exclusão vertical - manifestada pela sub-representação das mulheres em carreiras de maior prestigio e poder, bem como a exclusão horizontal - expressa a partir da pouca participação feminina em determinadas áreas do conhecimento.

É importante destacar que hoje, observam-se algumas mudanças no que se refere a inserção da mulher na ciência e tecnologia, no entanto, conforme mencionado anteriormente, por consequência do seu papel na esfera privada, que implica nos afazeres domésticos, cuidado com os filhos, dentre outras atividades, a dedicação aos estudos e produção científica não se apresenta nas mesmas condições que os homens.

Destaca-se que o nosso intuito de trazer a discussão sobre a mulher na ciência e tecnologia dá-se ao fato de compreendermos que o espaço da educação tecnológica e profissional, para além de uma escola, constitui-se por e para esses fins. Pensando no espaço escolar, Guacira Lopes Louro (1997) ao trazer para o debate as características ditas como femininas ou masculinas, acentua que levando em conta essa informação, muitos/as apontariam que a escola é feminina, tendo em vista a constituição de um corpo docente formado majoritariamente por mulheres e ao fato de que as atividades desenvolvidas nesse espaço são marcadas pelo cuidado, vigilância e educação, ações essas tradicionalmente tidas como femininas. Outros/as defenderiam que a escola é masculina, pois o conhecimento ali trabalhado é produzido pelos homens, a linguagem predominante e apontada como gramaticalmente correta é masculina. $O$ que pode-se delinear nessa questão, é a construção social que se faz presente nas constituições de gênero 
apontadas como constituidores e constituintes da escola. Tal como afirma Louro (1997, p. 89, grifos da autora),

\begin{abstract}
Ambas as argumentações apelam para noções com as quais usualmente concordamos e que reconhecemos nas nossas práticas escolares. O que fica evidente, sem dúvida, é que a escola é atravessada pelos gêneros; é impossível pensar sobre a instituição sem que se lance mão das reflexões sobre as construções sociais e culturais de masculino e feminino.
\end{abstract}

Partindo do resgate histórico acerca da temática da mulher na educação Schiebinger (2001, p. 61) nos mostra que as universidades foram inóspitas às mulheres desde sua fundação no século XII até o século XIX e, em alguns casos, até o início do século XX excluíam as mulheres do processo de educação/estudo. Foi a partir do século XIII na Itália, que algumas mulheres puderam estudar e lecionar em algumas universidades Conforme Schiebinger (2001, p. 61) "Elas com frequência prosperavam em campos, como a física e a matemática, considerados, hoje, especialmente resistentes às incursões femininas".

\title{
AS MULHERES DOCENTES NO IFPR: O QUE OS DADOS NOS MOSTRAM
}

Nesta seção buscaremos apresentar alguns dados concretos ${ }^{5}$ que nos levarão a refletir se dentre o quantitativo de professoras no Campus Curitiba, elas se fazem presente em proporção de igualdade na docência das disciplinas técnicas em todos os cursos, em quais disciplinas observamos sua presença e quais as coordenações desses cursos, são ocupadas por mulheres. A partir dos dados iniciais da pesquisa, consta no corpo docente do Campus: duzentos e vinte servidores/as, destes: cento e três são mulheres e cento e dezessete são homens. Observando esses dados a partir da disposição em gráficos temos:

Gráfico1: Corpo docente do IFPR.

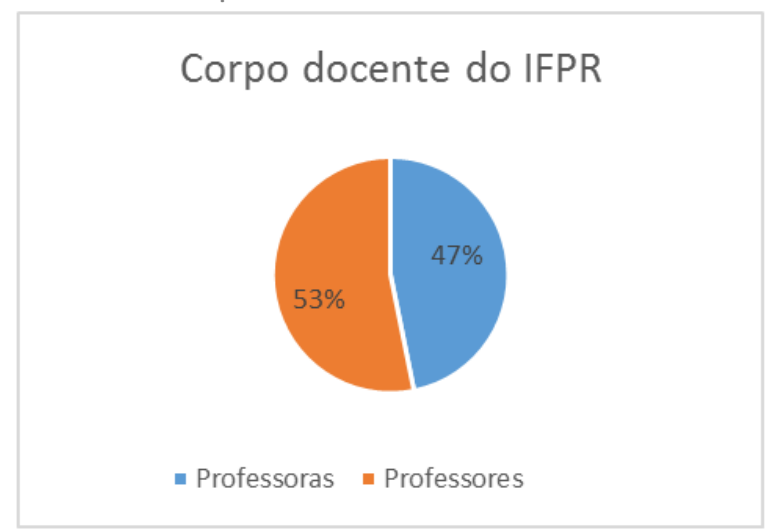

Fonte: Sitio do IFPR Campus Curitiba- Elaboração própria.

Para traçarmos uma análise acerca da distribuição com o intuito de verificarmos a proporção de professoras nas disciplinas técnicas dos cursos técnicos, dividimos os cursos ofertados pela instituição em três grandes áreas: Humanas', Engenharias ${ }^{8}$ e Saúde ${ }^{9}$. Essa divisão foi estabelecida como forma de melhor ilustrar a participação dos/as docentes e verificar a proporcionalidade na ocupação dos cargos entre as professoras e professores. 
Verificamos haver nos cursos da área das engenharias o total de 42 docentes, sendo que há a presença de 11 professoras lecionando às disciplinas técnicas para uma proporção de 31 professores. Nos cursos pertencentes às áreas de humanas verificamos haver 42 docentes, sendo ocupadas por 24 professoras contra 18 professores; já nas disciplinas que envolvem as áreas da saúde, constatamos o total de 34 docentes para uma proporção de 24 professoras e 10 professores.

Isso pode ser melhor visualizado ao observarmos o gráfico 2:

Gráfico 2: Professoras/es lecionantes das disciplinas técnicas de acordo com a classificação nas três áreas.

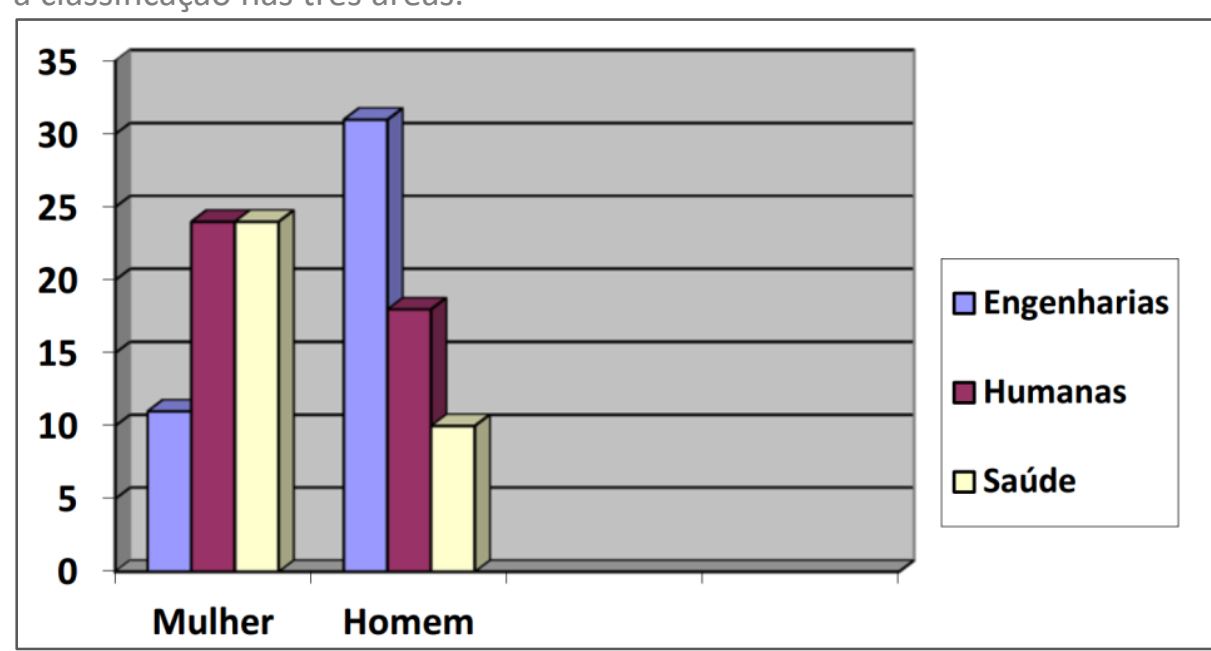

Fonte: Listagem interna de professores/as. Acesso em 03 ago. 2016. Elaboração própria.

Partindo para a análise dos números referentes às coordenações de curso, verificamos que nos cursos integrados, de um total de oito vagas, quatro mulheres foram eleitas para esses $\operatorname{cargos}^{10}$. Ou seja, há uma proporção igualitária entre homens e mulheres. Nos cursos subsequentes, de um total de dezesseis, nove deles tem suas coordenações ocupadas por professoras ${ }^{11}$. Como é possível observar, nesses cursos há uma prevalência de mulheres enquanto coordenadoras. Pode-se inferir que a função de coordenação de curso, vem sendo requisitada para e pelas mulheres. Essa função, na instituição, comumente está associada as questões de organização pedagógica e curricular dos cursos, bem como acompanhamento das/os estudantes.

No que concerne à distribuição dos cargos de Coordenação dos Cursos Técnicos constatamos que nos 10 cursos provenientes das Engenharias a presença de mulheres nos cargos de Coordenação de Curso é de 02 professoras, considerando o total de cursos disponíveis esse número representa $20 \%$ de mulheres como coordenadoras dos cursos dessa área. Dentre os 09 cursos provenientes da área das Ciências Humanas há 07 Coordenadoras de Curso. Nesses cursos a representatividade das professoras como coordenadoras é de $77 \%$. Já nos 05 cursos provenientes das áreas da Saúde, verificamos a presença de mulheres na Coordenação de 04 Cursos, assim, observa-se que nessa área $80 \%$ das coordenações são ocupadas por mulheres. 
Gráfico 3: Proporção da distribuição dos Cargos de Coordenação dos Cursos nas três áreas entre Professoras X Professores.

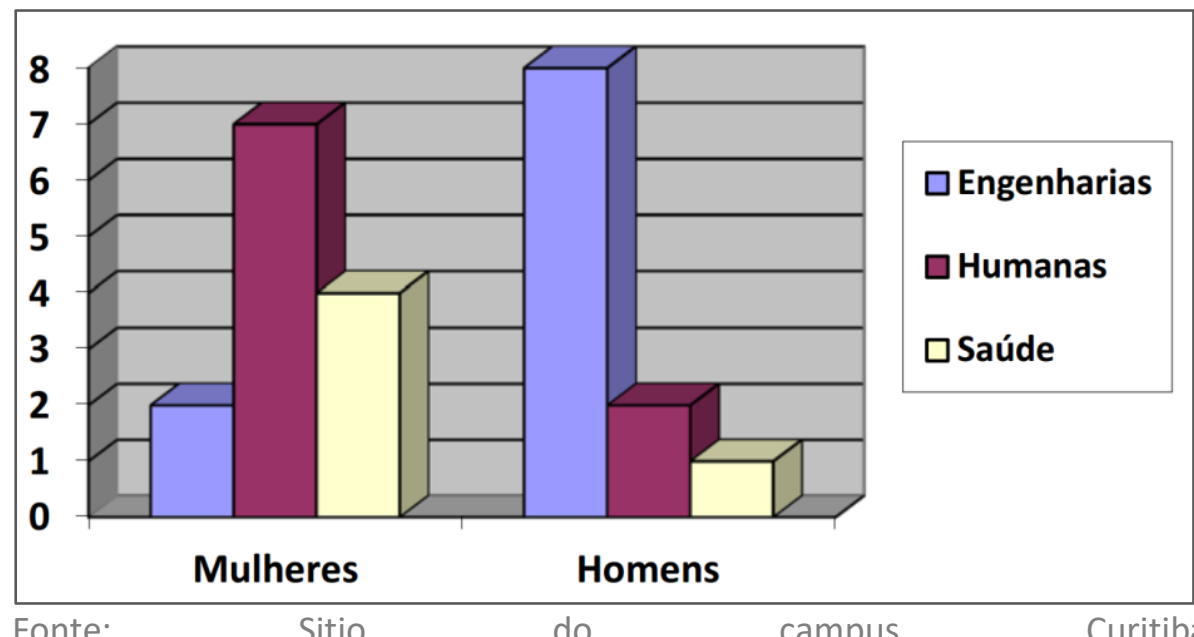

(http://curitiba.ifpr.edu.br/menuacademico/cursos/) acesso em 03 de agosto de 2016 - Elaboração própria.

Ao consideramos a distribuição docente por lecionamento de disciplinas e inserção destes/as profissionais encontramos as seguintes situações: docentes afastados para pós-graduação; disciplinas do núcleo comum ${ }^{12}$, disciplinas de áreas técnicas ${ }^{13}$, cargos administrativos ${ }^{14}$ e cargos de gestão ${ }^{15}$. No que tange aos professores (homens) a distribuição nessas categorias foi a seguinte:

Gráfico 4: Professores x distribuição em áreas de atuação.

\section{Professores}

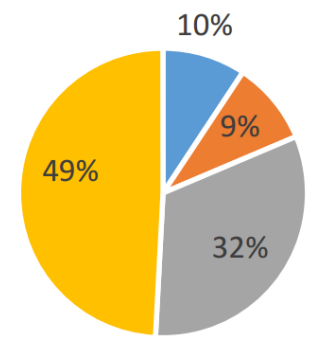

$$
\begin{aligned}
& \text { - Afastamento pós graduação = Cargos de gestão } \\
& \text { - Disc. Núcleo comum } \quad \text { - Disciplina Técnica }
\end{aligned}
$$

Fonte: Listagem interna de professores/as. Acesso em 03 ago. 2016. Elaboração própria. 
Em que pese à distribuição das professoras nas categorias mencionadas anteriormente temos:

Gráfico 5: Professoras X distribuição em áreas de atuação:

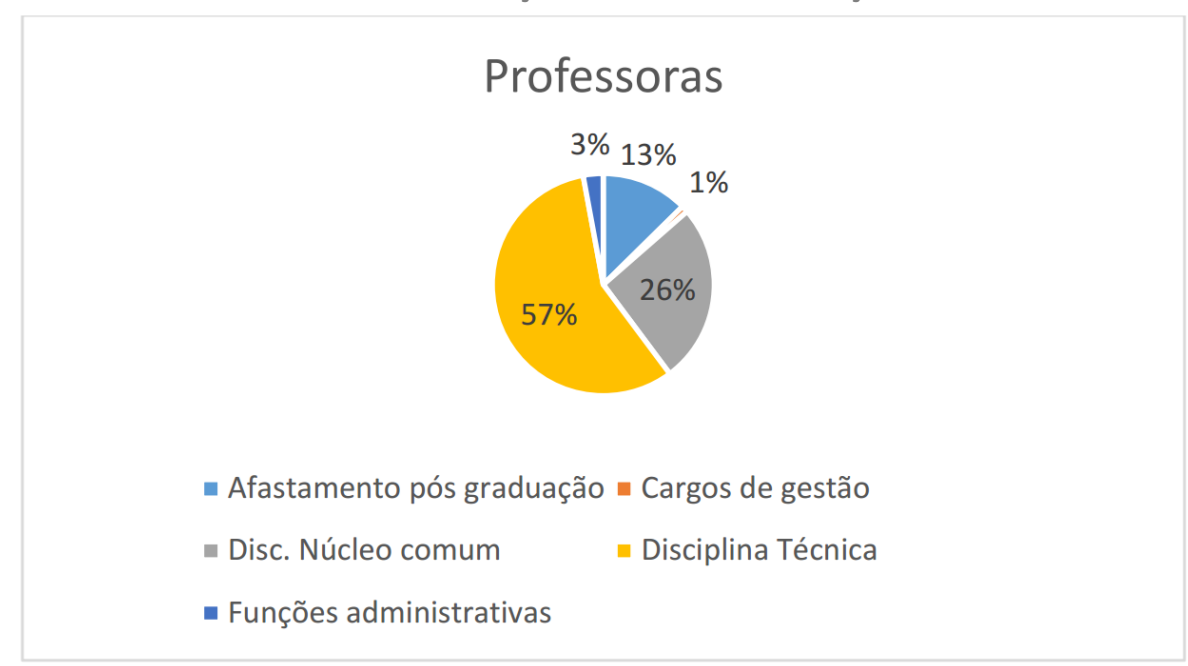

Fonte: Listagem interna de professores/as. Acesso em 03 ago. 2016. Elaboração própria.

Diante dos dados apresentados podemos inferir que há uma distribuição igualitária entre os/as docentes em que pese à distribuição das disciplinas. Observa-se que mais mulheres tem se afastado para cursos de pós-graduação strito sensu. Verifica-se, no entanto, que quando observamos à distribuição dos cargos de gestão as mulheres não têm ocupado esses espaços de forma igualitária aos homens, estando essas, em maioria, em atuação administrativa, o que não é observado no caso dos professores, dos quais, atualmente, nenhum ocupa cargos administrativos.

\section{CONSIDERAÇÕES FINAIS}

A atuação da docente no Campus Curitiba analisada à luz dos conceitos: origem da educação, educação profissional tecnológica, trabalho, divisão sexual do trabalho e inserção da mulher na ciência nos mostram inúmeras similaridades. No que tange a história da educação e educação profissional tecnológica se verifica que ela é fortemente influenciada pelas necessidades do trabalho leia-se capitalismo. Desta forma, isso também se reflete no acesso das mulheres ao mercado de trabalho.

Ao longo da história da inserção da mulher na ciência constatamos se tratar de uma participação instável e de acordo com cada época ela possui avanços e retrocessos, tal qual ocorre com a educação.

A análise a que se pretendeu realizar além da expressão numérica buscou observar se os/as docentes se encontram no mesmo nível de atuação, pois vimos que historicamente as mulheres levam prejuízo na formação e inserção na universidade, seja na condição de discente ou docente. Os dados nos mostram que há um pequeno predomínio de homens atuando como docentes do IFPR Campus Curitiba. Em que pese às coordenações de curso as mulheres hoje são a maioria como coordenadoras. O que nos leva a problematizar as atividades 
desempenhadas nessa função, as quais se direcionam a organização e acompanhamento do curso e dos/das estudantes. Também se apresentam em número maior quando temos em vista solicitações de afastamento para pósgraduação, o que consideramos um avanço a progressão na carreira docente. Entretanto, as docentes se encontram em desvantagens numéricas em relação às indicações para cargos de gestão. Quanto a esse fator podemos mais uma vez inferir a influência da divisão sexual do trabalho, visto que para esses cargos há a necessidade de uma dedicação integral à instituição, o que também pode afastar as mulheres visto sua dupla jornada: casa (família, filhos, dentre outros) e trabalho. Nesse sentido, retomamos a contribuição de Schiebinger (2001, p. 16), que nos traz o conceito de teto de vidro, o qual pode ser definido como a barreira supostamente invisível que impede as mulheres de atingirem o topo de uma carreira ${ }^{16}$. Por fim, acreditamos que o desafio para a academia enquanto espaço para o desenvolvimento na qualidade de docente ou discente é trazer a reflexão de quais possibilidades para extinguir a disparidade entre homens e mulheres nos campos de trabalho nas ciências, bem como as possibilidades para que essas tenham as mesmas condições que os homens de exercer cargos de poder.

Destacamos que essa é uma análise que deve ser aprofundada e deve-se considerar os processos transitórios de ocupação dos cargos de gestão. Entretanto, hoje a realidade mostra-se desta forma. 


\title{
THE FEMALE TEACHING STAFF OF IFPR AND THE GENDER ISSUE: protagonists or supporting actors in the formation process of the technical courses?
}

\begin{abstract}
This article aims to present the results of a research that made it possible to know the female teaching staff locus of the Federal Institute of Paraná (IFPR) - Curitiba Campus. The Campus's teaching staff it is constituted by two hundred and twenty five employees, being a hundred and seven women and a hundred and eighteen men. Analyzing these numbers, we initially observe that there is no prevalence regarding gender relations; however it is incumbent to investigate in which areas they are acting. The research was based on the collection of documentary/institutional data, which, when having the results in hand, besides the arrangement in graphics, necessarily leads us to many reflections that denote a qualitative analysis. We believe, finally, that the results of this research may lead us to reflect on the insertion of women in Science and Technology, since the researched sociooccupational space is a place of formal education, with a view to science and technology development.
\end{abstract}

KEYWORDS: Teachers. Professional and technological education. Occupational space. 


\section{NOTAS}

${ }^{1}$ Os cursos integrados ofertados pelo Campus são: Administração, Contabilidade, Eletrônica, Informática, Mecânica, Petróleo e Gás, Processos Fotográficos e Programação de Jogos Digitais.

Os cursos subsequentes são: Administração, Edificações, Eletromecânica, Eletrotécnica, Enfermagem, Eventos, Massoterapia, Mecânica, Processos Fotográficos, Produção de Áudio e Vídeo, Prótese Dentária, Radiologia, Saúde Bucal, Secretariado, Telecomunicações e Transações Imobiliárias. Já os cursos superiores são Ciências Contábeis e Gestão Pública. A especialização ofertada pela instituição é em Educação Profissional e Tecnológica.

${ }^{2}$ Este item é parte da dissertação: Brincadeiras persistentes, desigualdades de gênero presentes: Relações de gênero na educação profissional e tecnológica, uma análise a partir da percepção de estudantes do IFPR- Campus Curitiba.

${ }^{3}$ Informação obtida na página oficial da instituição: http://reitoria.ifpr.edu.br. Acesso em 02 de fev. 2016

${ }^{4}$ Os referenciais aqui citados foram desenvolvidos primeiramente na dissertação Brincadeiras persistentes, desigualdades de gênero presentes: Relações de gênero na educação profissional e tecnológica, uma análise a partir percepção de estudantes do IFPR- Campus Curitiba.

${ }^{5}$ Os dados coletados para essa análise são oriundos de uma listagem institucional interna de coordenadores/as de cursos e listagem de servidores/as do Campus. Para a coleta de dados por áreas, as pesquisadoras criaram um documento, o qual, a partir de informações repassadas pela direção de ensino, foi alimentado.

${ }^{6}$ Os cursos técnicos são constituídos a partir dos referenciais propostos pelo Catalogo Nacional de Cursos Técnicos, esse documento contempla 12 eixos tecnológicos, tendo em vista essa amplitude, para uma melhor ilustração, neste trabalho, consideraremos as grandes áreas citadas.

${ }^{7}$ A área de Humanas engloba os Eixos: Gestão e Negócios, Produção Cultural e Design e Hospitalidade e Lazer - e os cursos ofertados pelo IFPR - Campus Curitiba são: Técnico em Administração (Integrado e Subsequente), Técnico em Contabilidade (Integrado), Técnico em Eventos (Subsequente), Técnico em Processos Fotográficos (Integrado e Subsequente), Técnico em Produção de Áudio e Vídeo (Subsequente), Técnico em Secretariado (Subsequente) e Técnico em Transações Imobiliárias (Subsequente).

${ }^{8}$ A área de Engenharias contempla os Eixos: Controle e Processos Industriais, Informação e Comunicação, Produção Industrial e Infraestrutura - e os cursos ofertados pelo IFPR - Campus Curitiba são: Técnico em Eletrônica (Integrado), Técnico em Mecânica (Integrado e Subsequente), Técnico em Informática (Integrado), Técnico em Petróleo e Gás (Integrado), Técnico em Programação de Jogos Digitais (Integrado), Técnico em Eletrotécnica (Subsequente), Técnico em Eletromecânica (Subsequente) e Técnico em Telecomunicações (Subsequente). 
${ }^{9} \mathrm{Na}$ área de Saúde está o: Ambiente Saúde e Segurança e contempla os seguintes cursos ofertados pelo IFPR - Campus Curitiba: Técnico em Enfermagem (Subsequente), Técnico em Radiologia (Subsequente), Técnico em Massoterapia (Subsequente), Técnico em Saúde Bucal (Subsequente) e Técnico em Prótese Dentária (Subsequente).

${ }^{10}$ As professoras ocupam os cargos de coordenadoras nos cursos Técnico em Administração, Técnico em Contabilidade, Técnico em Jogos Digitais e Técnico em Processos Fotográficos. Informação obtida em setembro de 2016.

${ }^{11}$ As professoras coordenam os cursos Técnico em Administração, Técnico em Secretariado, Técnico em Enfermagem, Técnico em Radiologia, Técnico em Saúde Bucal, Técnico em Massoterapia, Técnico em Edificações, Técnico em Eventos e Técnico em Produção de áudio e vídeo. Informação obtida em setembro de 2016.

${ }^{12}$ Núcleo Comum é a denominação do conjunto de disciplinas básicas (História, Filosofia, Matemática, Sociologia, Geografia, Língua Portuguesa, Língua Espanhola, dentre outras) e caracteriza-se pela atuação dos/as professores/as em todos os cursos da Instituição, diferentemente dos/as docentes das disciplinas técnicas, que via de regra atuam especificamente em um ou alguns cursos diretamente ligados a sua área de formação.

${ }^{13}$ Aqui denominamos disciplina técnica todas aquelas que não fazem parte do núcleo comum e estão ligadas diretamente à formação técnica necessária para os cursos.

${ }^{14}$ Professores/as que ocupam cargos administrativos, sem ter uma função gratificada e ou status de gestão.

${ }^{15}$ Nessa categoria consideramos os cargos de alta gestão como diretoria de campus, diretoria ou pró-reitoria no âmbito institucional de reitoria.

${ }^{16}$ Aqui consideramos a carreira e os cargos disponíveis nas instituições de ensino, especialmente no IFPR.

\section{REFERÊNCIAS}

CABRAL, Carla Giovana; BAZZO, Walter Antonio. As mulheres nas escolas de engenharia brasileiras: história, educação e futuro. Revista de Ensino de Engenharia, v. 24, n. 1, p. 3-9, 2005.

CARVALHO, Marilia Gomes de. Tecnologia e Sociedade. In: Bastos, João Augusto de Almeida. Tecnologia e Interação: publicação do Programa de Pós-graduação em Tecnologia - PPGTE/CEFET-PR. (Coletâneas "Educação \& Tecnologia" CEFETPR) Curitiba: CEFET-PR, 1998. 174p.

CARVALHO, Marília Gomes de. Estudos de Ciência, tecnologia e gênero: Rompendo paradigmas: In: Ciência, tecnologia e Gênero: Abordagens 
iberoamericanas. Marilia Gomes de Carvalho (org.). 1. Ed. Curitiba: ed. UTFPR, 2011.

CARVALHO, Marilia Gomes de; CASAGRANDE, Lindamir Salete. Mulheres e ciência: desafios e conquistas. Interthesis, 2011, v.8, n. 2, p. 20-35.

ENGUITA, Mariano Fernandez. A face oculta da escola: educação e trabalho no capitalismo. Porto Alegre: Artes Médicas, 1989.

FREITAS, Barbara. Escola, Estado e Sociedade. São Paulo. Editora Moraes Ltda. 1986, p. 15-43.

FRIGOTTO, Gaudêncio. Fundamentos científicos e técnicos da relação trabalho e educação no Brasil de hoje. In: LIMA, Julio Cesar França; NEVES, Lucia Maria Wanderley. Fundamentos da Educação Escolar do Brasil Contemporâneo. São Paulo: Fiocruz/EPSJV, 2007, p. 241-287.

HIRATA, Helena. Nova divisão sexual do trabalho? Um olhar voltado para a empresa e a sociedade. São Paulo: Boitempo Editorial, 2002.

HIRATA, Helena; KERGOAT, Daniéle. Novas configurações da divisão sexual do trabalho. In: Cadernos de Pesquisa, v. 37, n. 132, p. 595-609, set./dez. 2007. Tradução de Fátima Murad. Disponível em: < http://www.scielo.br/pdf/cp/v37n132/a0537132.pdf>. Acesso em 09 set. 2015.

INCERTI, Tânia Gracieli Vega. Brincadeiras persistentes, desigualdades de gênero presentes: Relações de gênero na educação profissional, uma análise a partir da percepção de estudantes do IFPR- Campus Curitiba. 2017. 191 f. Dissertação (Mestrado em Tecnologia) - Universidade Tecnológica Federal do Paraná. Curitiba, 2017.

KUENZER, Acácia. Exclusão includente e inclusão excludente: a nova forma de dualidade estrutural que objetiva as novas relações entre educação e trabalho. In: SAVIANI, D.; SANFELICE, J.L.; LOMBARDI, J.C. (Org.). Capitalismo, trabalho e educação. 3. ed. Campinas: Autores Associados, 2005. p. 77-96.

LIMA FILHO, Domingos Leite Lima; QUELUZ, Gilson Leandro. A Tecnologia e a Educação Tecnológica: elementos para uma sistematização conceitual, Secretaria Estadual de Educação do Paraná, 2010. Disponível em:

<http://www.educadores.diaadia.pr.gov.br/arquivos/File/2010/artigos_teses/20 10/Pedagogia/atecnologiaedtecnologicaok.pdf>. Acesso em 11 mai. 2015.

MOURA, Dante Henrique; LIMA FILHO, Domingos Leite; SILVA, Mônica Ribeiro. Politecnia e formação integrada: confrontos conceituais, projetos políticos e contradições históricas da educação brasileira. Rev. Bras. Educ., Dez 2015, vol.20, no.63, p.1057-1080.

SCOTT, Joan. O enigma da igualdade. In: Estudos Feministas, Florianópolis, 13(1): 11-30, janeiro-abril/2005 
Recebido: 14 de fevereiro de 2017.

Aprovado: 03 de março de 2017.

Como citar:

INCERTI, Tânia Gracieli Vega.; CARVALHO, Ana Maria; CASAGRANDE, Lindamir Salete. As mulheres docentes do IFPR e a questão de gênero: protagonistas ou coadjuvantes no processo formativo dos cursos técnicos?. Cad. Gên. Tecnol., Curitiba, v. 10, n. 35, p. 40-57, jan./jun. 2017.

Correspondência:

Lindamir Salete Casagrande

Rua Eurides Cunha, 85, apto. 1325. 80320010, Curitiba.

Direito autoral:

Este artigo está licenciado sob os termos da Licença Creative Commons-Atribuição 4.0 Internacional.

(c) (1) 